\title{
Implicit theories of personal and social attributes: Fundamental mindsets for a science of wellbeing
}

\author{
Andrew J. Howell
}

\begin{abstract}
This paper argues for the fuller incorporation by wellbeing researchers of the implicit theories framework developed by social psychologist Carol Dweck and colleagues. This framework emphasises the role of entity ("fixed") and incremental ("growth") mindsets regarding personal and social attributes in the prediction and causation of psychological outcomes, including outcomes directly germane to feeling good and functioning well. Correlational, longitudinal, experimental, and meta-analytic findings are used to illustrate links between implicit theories and Seligman's dimensions of wellbeing: positive emotions, engagement, relationships, meaning, and accomplishment. Several research and practice implications of the implicit theories framework for the science of wellbeing are forwarded, such as the study of implicit theories of wellbeing and of interventions aimed at cultivating growth mindsets regarding wellbeing.
\end{abstract}

Keywords: implicit theories, incremental mindset, entity mindset, wellbeing, Carol Dweck

\section{Introduction}

A theoretical framework that is closely related to flourishing, thriving, and fulfilment; to learning, growth, and development; and to effort, dedication, and resiliency would reasonably be expected to appear often among perspectives considered fundamental to the field of wellbeing studies. Such an expectation would be bolstered by the framework's strong empirical support and its successful application to real-life contexts such as schools, the workplace, and relationships. It may therefore come as a surprise that just such a framework of understanding - the social psychological implicit theories framework - receives limited attention within the science of wellbeing and closely related fields of study. For example, the theory's core concepts (e.g., entity and incremental mindsets) make no appearance in Rusk and Waters' (2013) comprehensive bibliometric analysis of key terms characterising positive psychology. The current article strives to advance the greater incorporation of implicit theories research, theory, and interventions by the field of wellbeing studies.

In nearly three decades of research and theory development, Carol Dweck and colleagues have spearheaded the discovery of numerous correlates and consequences of the extent to which personal or social attributes, such as ability, personality, relationships, and emotion regulation, are viewed as fixed or malleable (Dweck, 1999, 2012; Dweck, Chiu, \& Hong, 1995; Dweck \& Leggett, 1988). People who endorse an entity theory (or fixed mindset) perceive such attributes as relatively stable; for example, some people adopt a view of personality as immutable. People who endorse an incremental theory (or growth mindset) perceive such attributes as amenable to ongoing development; for example, some people adopt a view of personality as malleable. Importantly, people's implicit theories - beliefs that are "deeply held, but rarely articulated" 
(Molden \& Dweck, 2000, p. 140) - have numerous implications for subsequent psychological functioning; broadly speaking, evidence suggests that adoption of an incremental mindset, relative to an entity mindset, is associated with more adaptive cognitive and behavioural consequences, such as greater resilience when confronted with adversity (Dweck et al., 1995).

The current paper seeks to underscore the relevance of the implicit theories framework to the science of wellbeing by illustrating how implicit theories research is pertinent to each element of Seligman's (2011) multidimensional wellbeing theory: positive emotion, engagement, relationships, meaning, and accomplishment (i.e., PERMA). Seligman (2011) and Jayawickreme, Forgeard, and Seligman (2012) conceptualise positive emotion as the regulation of both positive and negative emotion in order to maximise positive emotional experience; engagement as the setting of and striving toward goals that allow one to be challenged by, to be interested and absorbed in, and to exert mastery over what one is doing; relationships as the maintenance of positive interactions with others; meaning as contributing to something beyond oneself; and accomplishment (or achievement) as the attainment of success within a particular performance domain.

The rationale for employing wellbeing theory (i.e., the PERMA model) as a framework for considering the importance of implicit theories for wellbeing studies is manifold. First, wellbeing theory includes aspects of both hedonic and eudaimonic wellbeing; while positive emotional experience is especially relevant to feeling well, engagement, relationships, meaning, and accomplishment are characteristics of living well (Jayawickreme et al., 2012). Second, the PERMA dimensions overlap significantly with alternative wellbeing theories, such as the dimensions of Ryff's (1989) psychological wellbeing. Finally, wellbeing theory is bolstered by recent empirical work (Coffey, Wray-Lake, Mashek, \& Branand, 2016; Kern, Waters, \& Adler, 2015; Lambert D'raven \& Pasha-Zaidi, 2016), including support for the theorised structure of wellbeing.

The following sections address, in turn, how findings from implicit theories research relate to positive emotion, engagement, relationships, meaning, and accomplishment. In each case, a sample of research is reviewed to illustrate the pertinence of implicit theories to the particular wellbeing dimension. Given that the purpose of the current article is simply to make the case that the implicit theories framework is highly relevant to the study of wellbeing, no attempt is made to review such research exhaustively; however, where available, meta-analyses are reviewed in order to establish the robustness and generalisability of findings. The discussion of implications following each section is also intended to be illustrative rather than exhaustive; a fuller consideration of several key implications of the implicit theories framework for the study of wellbeing occurs in a later section.

\section{Implicit theories research and dimensions of wellbeing}

\subsection{Positive emotion}

Implicit theories are relevant to emotional experience in two key ways: first, people with incremental and entity mindsets differentially experience positive and negative emotion as they function within various domains (e.g., interpersonal interactions, academic pursuits). Second, emotional experience is itself an attribute for which people hold implicit theories concerning its malleability or immutability.

Much research has examined how implicit theories predict emotional experience within various realms of functioning. As a recent example, Yeager et al. (2014) presented correlational and experimental evidence showing that among US high school students, implicit theories of personality differentially predict emotional reactions to a computer-based social rejection experience. In a longitudinal study, those with an entity mindset (i.e., those who endorse items 
such as "Bullies and victims are types of people who really can't be changed") experienced more anxiety and stress and a less positive view of themselves in response to social rejection compared to those with an incremental mindset. Moreover, later in the school year, global stress was higher and both physical health and achievement were lower among students with an entity mindset. In two subsequent experimental studies, American high school students were led to adopt an incremental mindset of attributes related to peer conflicts by reading information suggesting that neither victims nor bullies are "fixed" in their ways, by reading testimonials of more senior students regarding how an incremental mindset can help during peer conflicts, and ultimately by writing a narrative of this perspective that they were led to believe would be presented to younger students. Cultivation of an incremental mindset led to less anxiety and stress, and to a more positive self-view, in response to social rejection (and to less global stress, better health, and higher achievement later in the year), thereby demonstrating the causal impact of implicit theories on emotional experience and additional outcomes.

Two recent meta-analyses support the general association between implicit theories and emotional experience. Burnette, O’Boyle, VanEpps, Pollack, and Finkel (2013) examined the association between implicit theories and the experience of both negative emotions and positive expectancies during the self-monitoring of progress toward goals. Across 13 studies, an entity mindset was significantly and positively associated with negative emotional experience $(r=.23)$. Across 43 studies, an incremental mindset was significantly and positively associated with positive emotional expectancies, such as optimism $(r=.15)$. Schleider, Abel, and Weisz (2015) examined the association between implicit theories and numerous indices of youth distress and mental health problems. Across 17 studies, the entity mindset was significantly and positively associated with mental distress $(r=.25)$. Therefore, there is robust evidence that a fixed mindset is predictive of negative emotional experience, suggesting the possibility that the cultivation of an incremental mindset is a route toward optimal emotional experience.

The science of wellbeing also stands to gain insight into adaptive emotional functioning from recent work concerning implicit theories of emotion; that is, the extent to which people view their emotional propensities as fixed or mutable. Those with an incremental theory of emotional experience may derive emotional and other benefits from such a mindset relative to those with an entity theory of emotional experience. Tamir, John, Srivastava, and Gross (2007), in a longitudinal study of American students transitioning into university, showed that those with a fixed view of emotions (i.e., endorsing items such as, "No matter how hard they try, people can't really change the emotions that they have") engaged in poorer emotional self-regulation during the transition, experienced fewer positive and more negative emotions over a 10-week period, and had lower psychological wellbeing at the end of their first year of studies. In two additional studies with American undergraduate students, an entity theory of emotion predicted less reliance on cognitive reappraisal as an emotion-regulation mechanism along with reduced selfesteem and life satisfaction (De Castella et al., 2013) and greater use of emotional avoidance (Kappes \& Schikowski, 2013).

To examine the causal impact of implicit theories of emotion, Kneeland, Nolen-Hoeksema, Dovidio, and Gruber (2016) experimentally manipulated incremental and entity beliefs regarding emotion by having undergraduate students in the US read a series of arguments as to why emotion can be viewed as malleable or as fixed, respectively. In order to induce feelings of social anxiety, participants next gave an audio- and video-recorded speech that, they were told, the investigators would watch at a later time. Finally, participants rated their use of cognitive reappraisal and suppression as emotion-regulation strategies during their speech. Results showed that those led to view their emotional experience as malleable made greater use of 
cognitive reappraisal during the stressful speech task than those led to view their emotional experience as fixed. No differences arose concerning the use of suppression.

\subsubsection{Summary and implications}

There is evidence that less adaptive emotional functioning is associated with viewing attributes such as personality and ability as fixed, and that adopting a fixed view of emotional experience itself is associated with less adaptive emotion regulation and lower wellbeing. Wellbeing researchers could play a significant role in extending these lines of research. For example, research is needed on the extent to which implicit theories predict emotions following positive experiences and on the possibility that positive emotion itself fosters incremental mindsets (e.g., perhaps as one aspect of the broadening function of positive affect; Fredrickson, 2001). With respect to implicit theories of emotional experience, studies are needed on whether incremental theories of positive emotions such as joy or hope are associated with adaptive outcomes, and whether people can hold contrasting implicit theories for positive versus negative emotions. Finally, as discussed later, it may be that there are trait and state variations in people's implicit theories of wellbeing (i.e., beyond emotional experience), such that an incremental view of wellbeing is associated with, and perhaps promotive of, positive emotional experience and positive functioning.

\subsection{Engagement}

There are two important ways in which implicit theories are relevant to engagement. First, implicit theories affect goal adoption, with goal types differing from each other with respect to their adaptive nature. Second, implicit theories affect goal striving, with subjective experiences during goal pursuit varying from helplessness to mastery. Since goal adoption and goal striving are highly relevant to positive personal functioning, an increased understanding of the role of implicit theories in such goal-related processes may carry important implications for wellbeing studies.

Dweck and colleagues (Dweck, 1999; Dweck et al., 1995; Dweck \& Leggett, 1988) posited that an entity mindset promotes the adoption of performance-related goals (i.e., goals concerned with demonstrating one's fixed level of competence relative to the performance of others), whereas an incremental mindset promotes the adoption of mastery-related goals (i.e., goals concerned with developing one's alterable level of competence relative to an absolute standard). Research supports the predicted associations between implicit theories and goal adoption. For example, Cury, Elliot, Da Fonseca, and Moller (2006) conducted two studies in which they assessed temporal relationships among implicit theories and achievement goals. In a longitudinal field study, French adolescents completed measures of implicit theories concerning math ability (e.g., "One has a certain level of ability in math, and there is not much one can do to change it"), and, at a later date, achievement goals. Results showed that an entity mindset predicted the endorsement of performance goals, whereas an incremental mindset predicted the endorsement of mastery goals.

In a second study by Cury et al. (2006), French adolescents participated in a laboratory-based experiment in which they were randomly assigned to read either an entity or an incremental account of a specific cognitive ability that was the focus of a task they had just completed. They then completed a measure of their goals for an upcoming performance on the same task. Consistent with the results of Study 1 , those led to have an entity mindset, relative to those led to have an incremental mindset, were more likely to adopt performance goals and less likely to adopt mastery goals. Notably, both studies by Cury et al. (2006) also showed systematic 
associations between implicit theories and task performance, such that an incremental mindset was associated with higher performance than an entity mindset (see below re: the wellbeing dimension of accomplishment). These studies indicate that there may be advantages to the promotion of incremental beliefs regarding ability, as such beliefs foster adoption of goals toward the development (and not just demonstration) of one's competence.

People also differ in the manner in which they approach their goals; such differences in goal striving (in addition to goal adoption) are predictive of important outcomes. In an experiment pertaining to the role of implicit theories in goal striving, Nussbaum and Dweck (2008, Study 1) induced incremental and entity mindsets concerning intelligence among American undergraduate students. Participants were then told that they performed at the $37^{\text {th }}$ percentile on a speed reading task. Finally, participants were invited to choose to examine strategies ostensibly used by other students who performed better or worse than they themselves had performed. Results showed that students induced to adopt an entity mindset chose to examine strategies employed by others whose performance was poorer, whereas students induced to adopt an incremental mindset chose to examine strategies employed by others whose performance was better. Therefore, incremental mindsets are associated with more adaptive goal striving following adversity.

In the meta-analysis of Burnette et al. (2013), an incremental mindset was shown to be significantly and positively associated with mastery goals $(r=.19$ across 36 studies) and significantly and negatively associated with performance goals ( $r=-.15$ across 30 studies). The pertinence of implicit theories to goal striving was also revealed in the meta-analysis of Burnette et al. (2013); specifically, an incremental mindset was inversely related to helpless-oriented strategies such as procrastination ( $r=-.24$ across 19 studies) and positively related to masteryoriented strategies such as planning ( $r=.23$ across 35 studies). Notably, Burnette et al. (2013) also showed that associations between implicit theories and both goal adoption and goal striving were moderated by the presence or absence of a personal setback, or "ego threat." An incremental mindset was more strongly associated with mastery-related goals and masteryrelated tactics under conditions of ego threat.

\subsubsection{Summary and implications}

There is robust evidence of associations between implicit theories and both goal setting and goal striving, with incremental mindsets being reliably more associated with adaptive goal choice and adaptive strategy choice relative to entity mindsets. From the standpoint of wellbeing research, it would be informative to examine whether a well-documented marker of task engagement, the experience of flow (Csikszentmihalyi, 1996), is associated with implicit theories regarding that particular performance domain. For example, a sense of personal control is one marker of flow experiences, a feature that characterises an incremental mindset more than an entity mindset. Perhaps those prone (or led) to harbor incremental beliefs regarding their task performance would experience moments of flow more frequently than those harboring entity beliefs.

Wellbeing researchers could also consider the role of implicit beliefs within their own goaloriented theories and goal-oriented interventions. As an example, King's (2001) best possible selves intervention involves people imagining the future self toward which they most aspire; this practice is associated with boosts in wellbeing. People's implicit theories regarding attributes emphasised in their future selves (e.g., ability level) may moderate the impact of such an intervention; that is, people may differ in the extent to which they view their future selves as malleable, with incremental beliefs regarding future possible selves associated with higher gains in wellbeing relative to entity beliefs. Moreover, the cultivation of an incremental mindset 
regarding future possible selves may serve to increase the impact of the best possible selves intervention.

\subsection{Relationships}

Two ways in which implicit theories affect relationships are considered herein. First, people hold implicit theories regarding the extent to which their relationships are fixed or malleable. Second, people hold implicit theories regarding the extent to which those with whom they interact are amenable to change. Both sets of beliefs are associated with significant implications for the quality of one's relationships. Given the focus upon relatedness and belongingness as key markers of a life well-lived, the role of implicit theories in this life domain holds significant import for a science of wellbeing.

Knee (1998) initiated the study of implicit theories regarding romantic relationships more than 15 years ago. In their reviews of this literature, Knee, Patrick, and Lonsbary (2003) and Knee and Petty (2013) characterise growth beliefs as a mindset wherein relationships can be maintained and conflicts overcome through effort and problem-solving, whereas they characterise destiny beliefs as a mindset wherein relationships either are or are not "meant to be" (see also the work-itout and soulmate beliefs identified by Franiuk, Cohen, \& Pomerantz, 2002). Growth beliefs are assessed with self-report items such as "The ideal relationship develops gradually over time," whereas destiny beliefs are assessed with such items as "To last, a relationship must seem right from the start" (Knee et al., 2003, p. 43).

Research by Knee, Patrick, Vietor, and Neighbors (2004, Study 1) illustrates important outcomes predicted by destiny and growth relationship mindsets. American undergraduates involved in romantic relationships completed measures of growth and destiny beliefs, relationship conflict, and relationship commitment. They then completed a diary entry for every disagreement that they experienced with their partners over a 10-day period, rating both the extent to which the problem was resolved and their momentary level of relationship commitment. Findings revealed that those higher in growth beliefs, relative to those lower in growth beliefs, remained more committed to relationships, despite unresolved disagreements with their partner.

Additional findings corroborate that implicit theories of relationships are predictive of important outcomes. Chen, DeWall, Poon, and Chen (2012) showed that a destiny mindset is associated with more anger and aggression in response to ostracism. Cobb, DeWall, Lambert, and Fincham (2013) showed that a growth mindset in romantic and nonromantic relationships predicted lower relationship violence. Overall, there is converging evidence that growth beliefs regarding relationships are associated with adaptive outcomes, particularly within the context of relationship challenges.

With regard to implicit theories of others' behavior, research reveals that an incremental mindset toward others is associated with more benign perceptions of others' transgressions. Yeager, Trzesniewski, Tirri, Nokelainen, and Dweck (2011, Study 3) randomly assigned Finnish adolescents to read either an article aimed at inducing an incremental mindset toward bullies or a control article. In the incremental condition, the article described a protagonist who was bullied and who subsequently learned that bullies could come to change their characteristics. Participants then rated their desire for vengeance; they judged characterological as well as more situational and developmental attributions for bullying; and they rated the degree to which they would feel shame, sadness, and hatred toward the transgressor. Results showed that the induction of an incremental mindset led to reduced desire for revenge, and that this was mediated by reduced "bad-person" attributions and reduced feelings of shame and hatred. 
Implicit theories are associated also with the tendency to make hostile attributions for another's ambiguous behavior. In a recent meta-analysis, Yeager, Miu, Powers, and Dweck (2013) showed that, among eight independent samples of American students in grades 8 through 10 , an entity mindset predicted a hostile attribution bias $(r=.18)$ and desire for vengeance $(r=$ .23) in response to either a hypothetical or a simulated social exclusion. Greater civility appears to correspond with viewing another's behaviour as less trait-like and more malleable.

\subsubsection{Summary and implications}

Studies demonstrate that an incremental mindset regarding relationships is associated with adaptive relationship outcomes, such as ongoing commitment during times of conflict. The role of implicit theories regarding relationships has been under-investigated within the context of harmonious or pleasant interactions with relationship partners; here, future work could examine whether incremental beliefs regarding relationships are related to beneficial interactions, even in the absence of relationship challenges. Future investigations could also examine whether other adaptive relationship processes, such as active-constructive responding in response to a partner's recent success or forgiveness in response to a partner's recent transgression, are associated with incremental beliefs regarding relationships. Future work is also needed on whether motivation for, or amenability to, relationship-oriented interventions is affected by the extent to which relationships are viewed as fixed or malleable. Finally, research is needed on whether the inculcation of growth mindsets regarding relationships strengthens intimate partnerships.

The reviewed research also shows that an incremental mindset regarding the behaviour of others is associated with a more pro-social, tolerant response to them. Here, the role of implicit beliefs regarding others' behaviour within the context of positive interactions with others needs investigation. From the standpoint of wellbeing interventions, it would be fruitful to consider whether the impact of interventions aimed at improving interpersonal functioning are moderated by individual differences in implicit beliefs regarding others. For example, parents who are led to adopt views that emphasise their children's amenability to growth, development, and change may be more responsive to positive parenting interventions relative to parents who hold more fixed views of their children's characteristics. Finally, those interested in studying workplace interactions could follow up findings that incremental beliefs among managers concerning employee functioning are predictive of managers' subsequent commitment to coaching those employees (Heslin, Vandewalle, \& Latham, 2008).

\subsection{Meaning}

Two ways in which implicit theories are pertinent to the wellbeing dimension of meaning are, first, that implicit beliefs may foster transcendence beyond the self (the aspect of meaning emphasised by Seligman, 2011), and, second, that implicit theories generally affect the meaning with which experiences are imbued. According to Wong (2011), these two aspects of meaning represent a major source of meaning (self-transcendence) and a major function of meaning (understanding, including self-understanding). Wellbeing researchers' understanding of meaning may benefit from incorporating findings concerning the role of implicit theories in meaning-making.

With respect to the self-transcendent aspect of meaning, there is evidence that an incremental mindset can be more conducive to helping others and to viewing others as similar to oneself in comparison to an entity mindset. In two studies, Karafantis and Levy (2004) recruited $5^{\text {th }}$ and $6^{\text {th }}$ graders in the US to complete measures of implicit theories concerning the malleability of personality, their attitudes towards disadvantaged children, and their volunteer activities. 
Results showed that those with an incremental mindset reported more positive attitudes toward disadvantaged children and a greater propensity for helping others. Therefore, an incremental view of others was predictive of transcending self-interest for the sake of others' welfare.

In a series of seven studies, Schumann, Zaki, and Dweck (2014) showed that individual differences in, and manipulations of, implicit theories concerning the malleability of one's empathic response to another predicted empathic effort in challenging situations. In their sixth study, for example, Schumann et al. (2014) manipulated an incremental or entity mindset regarding empathy among American undergraduate students, and then had students estimate the number of hours they would be willing to contribute to a campus-wide cancer campaign, including a high-effort activity (i.e., volunteering at a social support group for those with cancer) and two lower-effort activities (i.e., volunteering at a cancer awareness booth or at a walkathon). Results showed that those induced to adopt a malleable view of empathy volunteered a greater number of hours than those induced to adopt a fixed view of empathy, but only for the higheffort activity. Therefore, incremental mindsets predict greater expression of empathy toward others when such empathy may otherwise be lacking.

Concerning the function of meaning in facilitating understanding, implicit theories are viewed as affecting the overall interpretation and significance that people place on their experiences (Molden \& Dweck, 2000, 2006). Plaks, Levy, and Dweck (2009) argue that implicit theories provide people with "cornerstones of meaning" in that entity and incremental mindsets involve additional beliefs which "cohere into structured meaning systems that help individuals to construct a rich understanding of a person's behavior..." (p. 1070). Given that a key aspect of understanding is self-understanding (Wong, 2011), findings that illustrate that implicit theories affect self-conceptions following self-relevant experiences are of particular importance. For example, in a series of studies on American $5^{\text {th }}$ graders, Mueller and Dweck (1998) showed that receiving praise for one's intelligence following successful task performance, relative to praise for one's effort, generated a pattern of responses to a subsequent failure experience indicative of a negative self-view, including attributing the setback to lack of ability and concealing the poor performance from others. Therefore, encouraging an entity mindset relative to an incremental mindset regarding successful performance created a unique cascade of self-understanding in response to later adversity.

A more recent test of the effects of implicit theories on self-related inferences in response to adversity was provided by Lilgendahl, McLean, and Mansfield (2013). Community-residing adults in the US completed a narrative of a trauma incident and of a transgression incident from their past. These incidents were coded as to the extent to which they revealed healthy meaningmaking (i.e., themes of "self-growth") or unhealthy meaning-making (i.e., themes of either a "damaged self" or a "bad self"). Participants also completed a measure of implicit theories of personality. Results showed that an incremental mindset regarding personality was associated with more self-growth themes in trauma narratives and fewer bad-self themes in transgression narratives. These findings are consistent with the notion that implicit theories provide a route through which adverse experiences come to be associated with either healthy or maladaptive self-understandings.

An additional line of research further underscores the meaning-making function of implicit theories. In a series of experiments, Plaks, Grant, and Dweck (2005) showed that people are motivated to regain their implicit theory (be it an incremental or entity mindset) when that theory is threatened by the provision of theory-contradicting information. This suggests that implicit theories are associated with compensatory responses when threatened, consistent with the 
meaning maintenance model (e.g., Proulx \& Inzlicht, 2012), and, more generally, with the view that implicit theories provide meaning and coherence to experience.

\subsubsection{Summary and implications}

Implicit theories are related to meaning: an incremental mindset encourages greater selftranscendence (an important source of meaning-making), and an incremental mindset is associated with a more benign self-view following adverse experiences (an important function of meaning-making). Wellbeing research and practice stand to benefit from further exploration of the impact of growth and fixed mindsets on meaning-making. For example, self-transcendence in the form of selflessness or a quietened ego may reflect more malleable views of the self; such selflessness is argued to be a marker of authentic wellbeing (i.e., contentment and inner peace; Dambrun \& Ricard, 2011). As another example, implicit theories regarding positive empathy (i.e., reactions to others' positive feelings; Sallquist, Eisenberg, Spinrad, Eggum, \& Gaertner, 2009) are ripe for future investigation, building upon extant findings concerning the role of implicit theories in empathic responses toward others' negative feelings.

The findings of Lilgendahl et al. (2013) and of Mueller and Dweck (1998) provide an impetus for considering the role of implicit beliefs in extracting meaning from positive life events, as studies have thus far focused upon the construal of negative life events. Future work could also examine meaning-related interventions and the possible role of the cultivation of incremental mindsets in the facilitation of adaptive responses to adversity, and, possibly, heightened selfacceptance. Wong's (2010) meaning therapy, for example, combines approaches from several psychotherapeutic traditions, including existential therapy and positive psychotherapy, to support and inspire the client's potential for hope and growth in the face of personal limitations or challenges. It may be that adopting a view of the self as malleable is an important process within such a therapeutic approach.

\subsection{Accomplishment}

A great deal of research underscores a significant association between implicit theories (e.g., of ability) and various achievement-related outcomes. Specifically, as suggested by previously reviewed studies by Yeager et al. (2014) and by Cury et al. (2006), an incremental mindset is frequently associated with higher achievement than an entity mindset, a pattern of findings with important implications for the work of those who value accomplishment as a component of wellbeing.

As a further example, Blackwell, Trzesnieski, and Dweck (2007) conducted two studies in which the longitudinal trajectory of adolescents' math performance was assessed in relation to their implicit theories of ability. In the first study, first-year junior high school students in the US completed measures of implicit theories, mastery goals, effort beliefs, helpless attributions in response to hypothetical failure, and positive strategy use in response to hypothetical failure. Math grades in the fall and spring of grade 7 and 8 served as criterion variables. Results showed that an incremental mindset was associated with the endorsement of mastery goals and effort beliefs, and with lower helplessness and greater use of positive strategies after failure. Moreover, an incremental mindset predicted attainment of higher math grades during the transition into junior high school relative to an entity mindset. Finally, path analysis showed that the association between an incremental mindset and math attainment was mediated by the motivational variables of mastery goals and positive effort beliefs, as well as by lower helpless attributions and higher positive strategy usage following failure. 
In a second study by Blackwell et al. (2007), $7^{\text {th }}$ grade students in the US were randomly assigned to experience either an eight-session intervention aimed at bolstering an incremental mindset about math ability or a control intervention. Results showed that the induction of an incremental mindset regarding math ability positively affected students' subsequent math grades (by stemming the decline in math grades otherwise observed among control participants). These studies suggest a significant role for the inculcation of an incremental mindset in fostering academic achievement.

The large-scale meta-analysis by Burnette et al. (2013) confirmed a significant association between incremental beliefs regarding ability and achievement ( $r=.09$ based on 55 studies). The small magnitude of this effect is in line with the theoretical expectation that implicit theories especially exert their influence in response to adversity (i.e., adversity moderates the association between implicit theories and achievement; Burnette et al., 2013).

\subsubsection{Summary and implications}

Those who view their ability level as malleable and as amenable to development ultimately perform at a higher level than those who view their ability level as fixed and invariant. Research could further examine the role of implicit theories in goal attainment outside of the academic domain, such as the workplace (i.e., positive organisational scholarship; Cameron \& Spreitzer, 2012), community service, and the playing field (Dweck, 2007). Also, the science of wellbeing could more fully incorporate the concept of an incremental mindset into its attempts to both predict and promote goal attainment. For example, the use of coaching to promote goal attainment could be evaluated to determine the role within such an intervention of incremental mindsets regarding performance. Grant, Curtayne, and Burton (2009) showed that a cognitivebehavioral and solution-focused coaching intervention applied to public health executives generated high goal attainment, resilience, and wellbeing; because these outcomes are associated with incremental mindsets, it is possible that some of the effect of the intervention was mediated by change in implicit beliefs.

\section{Implicit theories: Further implications for wellbeing studies}

To summarise, implicit theories research reveals that an incremental mindset is related to adaptive emotional experience, and that construing emotional experience itself as malleable is also adaptive. Implicit theories research on engagement and accomplishment shows that an incremental mindset is associated with adaptive goal setting and goal striving, and with higher levels of goal attainment. In the domain of relationships, an incremental mindset relative to an entity mindset is associated with more adaptive problem resolution in romantic relationships and with more benign views toward others. With respect to meaning, an incremental mindset, more than an entity mindset, is associated with transcendence of the self, and, more generally, with a pattern of sense-making in which personal setbacks are handled in a manner conducive to a positive self-view.

There are several ways in which the implicit theories framework may contribute to the general advancement of the field of wellbeing studies. First, evidence reviewed here suggests the possibility that an incremental mindset is a defining feature of flourishing (i.e., feeling good and functioning well; Keyes, 2005). Indeed, such a mindset resembles the psychological wellbeing dimension of personal growth, described by Ryff (1989) as characterising an individual who is "continually developing and becoming, rather than achieving a fixed state wherein all problems are solved" (p. 1071) and considered by Ryff to be the wellbeing dimension most resembling Aristotle's eudaimonia (i.e., the realisation of one's potential). The incremental mindset was also 
identified by Huta (2016) as an important aspect of eudaimonic functioning. In this vein, future work could examine the nomological web of associations between incremental and entity mindsets, on the one hand, and indices of eudaimonic and hedonic wellbeing, on the other. Moreover, researchers may be interested in studying the antecedents of an incremental mindset (e.g., in socialisation experiences) and the consequences of such a mindset in terms of additional adaptive processes or outcomes (e.g., greater optimism).

A second implication concerns the focus, especially within positive psychology, on the identification and development of character strengths. Indeed, according to wellbeing theory, positive feeling, engagement, relationships, meaning, and accomplishment all stand to benefit from the identification and application of one's strengths of character (Seligman, 2011). Although not directly applied to strengths of character, implicit theories research shows that attributing a person's successful or unsuccessful performance to a personality trait (i.e., a character strength) rather than to effort encourages a fixed mindset regarding that performance, resulting in low resilience (Mueller \& Dweck, 1998; Rattan, Good, \& Dweck, 2012). This suggests that identifying a person's psychological assets as characterological has potential drawbacks, a prediction borne out in recent research. Louis (2011) had undergraduate participants complete either an intervention aimed at talent identification or one aimed at strengths development. The former intervention focused upon identifying students' innate talents, whereas the latter intervention focused upon the development of talents through effort. Students' generalised implicit theories were assessed both pre- and post-intervention. Results showed that students in the talent identification condition evidenced reduced incremental beliefs from pre- to post-intervention, whereas no such change occurred in the strengths development condition. These findings are in line with the notion that an emphasis on innate talent fosters a fixed mindset and risks underemphasising the significant and necessary role of effort in converting personal talent to personal strengths. Further research could aim to extend these effects, such as by examining whether interventions aimed at strengths development are, in part, mediated by change in implicit theories toward reduced entity or enhanced incremental mindsets.

Third, the numerous and substantial ties between implicit theories research and wellbeing studies also point to the potential role of interventions aimed at improving individual and interpersonal functioning that are based upon the implicit theories framework. In fact, the intervention of inducing incremental mindsets among students to improve academic persistence and performance is now recognised among a list of so-called wise psychological interventions, defined as brief, precise interventions aimed at allowing people to flourish by addressing specific underlying psychological processes (Walton, 2014, p. 73). Wellbeing scholars would themselves be wise to incorporate interventions based upon implicit theories, premised upon the significant accumulation of experimental findings in which changes in mindset are followed by changes in positive feeling and positive functioning. For example, one could devise an intervention aimed at the cultivation of an incremental mindset across several domains of functioning (e.g., achievement, relationships, emotional functioning), the impact of which could be evaluated on various aspects of flourishing.

Fourth, given that wellbeing theorists are increasingly interested in understanding positive functioning under adverse circumstances (e.g., Wong, 2011), recent work concerning implicit theories of situations raises important implications for future investigation into people's views toward life's adversities. Cohen-Chen, Halperin, Crisp, and Gross (2014) showed that incremental views of long-entrenched intergroup conflicts (e.g., "Under certain circumstances and if all core issues are addressed, the nature of conflicts can be changed," p. 69) predicted both hope and conciliatory attitudes, and that the induction of an incremental mindset regarding such 
conflicts caused increased levels of hope and conciliation. These studies suggest a potentially fruitful line of investigation of people's implicit theories regarding situations that they must confront and bear, and the extent to which such theories are predictive of adaptive expectations, emotions, attitudes, and behaviors. For example, an incremental mindset regarding an aging parent's illness or an ongoing threat of job loss may predict heightened hope and resiliency. Moreover, the induction of such a mindset may positively impact a person's coping capacity. It may also be adaptive to hold an incremental mindset regarding an upcoming positive circumstance, such as a vacation, in that such a mindset involves looking forward to an event while allowing that it may not unfold exactly as planned.

Fifth, more research is needed on the conditions under which one mindset is or is not more adaptive than the other. McNulty and Fincham (2010) provided cogent examples of seemingly adaptive psychological processes (e.g., forgiveness, optimism) that are maladaptive under certain contexts. With respect to implicit theories, findings reviewed herein are supportive of the view that incremental mindsets are often more adaptive than entity mindsets, consistent with an argument put forth by Schneider (2001): “...a bias in favour of anticipating controllability .... may be more adaptive - and arguably more rational - than a neutral position" (p. 260). However, drawbacks of an incremental mindset have been identified: Dweck et al. (1995) argued that an incremental mindset is more effortful and complex than an entity mindset; Burnette et al. (2013) identified contexts wherein the self-regulatory strategies associated with an incremental mindset (e.g., mastery goals) are less efficient and effective than those associated with an entity mindset; Knee and Petty (2013) identified that persisting with a growth view of one's relationship in the face of partner maltreatment may be highly disadvantageous; and Knee et al. (2004) argued that destiny (entity-like) beliefs regarding romantic relationships carry potential benefits, such as imbuing the relationship with special meaning. More research examining the conditions under which incremental mindsets are or are not adaptive is required to refine and specify interventions aimed at their cultivation.

\section{Implicit theories of wellbeing}

A final implication of the implicit theories framework for the science of wellbeing is considered more extensively: people may hold implicit theories of wellbeing that are predictive of important wellbeing outcomes. Just as researchers differ in the extent to which they view wellbeing as amenable to change (Lyubomirsky, Sheldon, \& Schkade, 2005), such variability likely characterises laypeople. Some people likely hold a fixed mindset regarding wellbeing, believing that wellbeing is invariant and immutable. Others may hold an incremental mindset regarding wellbeing, believing that it is alterable and amenable to growth. An incremental theory of wellbeing may be more adaptive than an entity theory of wellbeing, given the general advantage of incremental over fixed mindsets in numerous domains. Indeed, a recent series of studies showed that people who viewed wellbeing as malleable had higher wellbeing than those who viewed it as fixed; moreover, those exposed to arguments in favour of the malleability of wellbeing (e.g., the role of attitudinal factors in wellbeing) endorsed activities conducive to wellbeing to a greater degree than those exposed to arguments in favour of the fixity of wellbeing (Howell, Passmore, \& Holder, 2015). In further research along these lines, incremental and entity mindsets concerning wellbeing could be measured or manipulated in order to examine whether they are associated with differential engagement in, and responsiveness to, wellbeing interventions. Implicit theories may moderate people's openness to engage in beneficial activities and their likelihood of a positive therapeutic response. It is also possible that the impact of wellbeing interventions is mediated by a change in implicit beliefs toward greater malleability. 
In addition, it may be informative to devise and test a full-fledged intervention aimed at the longer-term cultivation of an incremental mindset toward wellbeing. Following the manner in which incremental mindsets have been induced in previous research (e.g., Yeager et al., 2014), an incremental mindset toward wellbeing could be cultivated by exposing participants to information regarding the malleability of wellbeing, having participants read about others who have intentionally and successfully altered their level of wellbeing, and having them write persuasive communications to convince others to adopt a malleable view of wellbeing. Such a growth-oriented mindset could then be assessed for its enduring impact on measures of positive feeling and positive functioning. Moreover, the influence of such a mindset could be examined under conditions of adversity, such as the experience of stress, to examine whether adversity moderates the impact of wellbeing mindsets on wellbeing outcomes. Potential pitfalls of wellbeing mindset inductions also require consideration; for example, it will be important when cultivating an incremental mindset regarding wellbeing to emphasise the malleability of wellbeing rather than the valuing of wellbeing, given evidence that overly valuing happiness can reduce people's positive affect (Mauss, Tamir, Anderson, \& Savino, 2011) and induce feelings of loneliness (Mauss et al., 2012).

An intervention aimed at cultivating an incremental mindset regarding wellbeing may be conceptualised within Lyubomirsky and Layous' (2013) positive-activity model. This model concerns the impact of intentional cognitive and behavioral activities on wellbeing. The model specifies mediators of such effects, including positive emotions, positive thoughts, and positive behaviors, and it identifies moderators of such effects, including various features of the activity (e.g., its duration and frequency) and of the individual (e.g., baseline levels of wellbeing). Therefore, the testing of an intervention aimed at cultivating incremental beliefs regarding wellbeing could take place within the positive-activity framework in order to best comprehend how, with whom, and under what conditions its effects can be maximised.

\section{Summary, limitations, and conclusions}

Studies reviewed herein - including correlational, longitudinal, experimental, and metaanalytic approaches with participants across several countries and different age groups illustrate how implicit theories are associated with the PERMA wellbeing dimensions of positive emotion, engagement, relationships, meaning, and accomplishment. It bears emphasising that there are aspects of wellbeing that are not captured by the PERMA framework; therefore, the relevance of the implicit theories framework to these domains was not examined herein. In addition, there are models of wellbeing that differ significantly from the PERMA framework, such that the relevance of implicit theories to these alternative conceptualisations remains uncertain. However, some research reviewed above showed that implicit theories are associated with additional concepts and processes of interest to a wide array of wellbeing researchers, including life satisfaction, civility, empathy, and tolerance. In yet other research, the implicit theories framework has been applied to additional attributes associated with wellbeing, including creativity (e.g., Ramos \& Puccio, 2014), self-control (Job, Dweck, \& Walton, 2010), positive youth development (Vella \& Gilbert, 2014), and leadership (Burnette, Pollack, \& Hoyt, 2010). Therefore, numerous characteristics of adaptive functioning are predicted by peoples' implicit theories.

This paper also presented implications for future research arising from the application of implicit theories research to the PERMA wellbeing dimensions. Moreover, it more extensively outlined several lines of research to further explore the role of implicit theories in wellbeing, including further testing of the novel concept of implicit theories of wellbeing, evaluating an 
intervention aimed at cultivating an incremental view toward wellbeing, and exploring whether implicit theories regarding wellbeing moderate or mediate the impact of existing wellbeing interventions. These and other implications strongly point to the potential value of the implicit theories perspective for wellbeing studies.

Finally, and of even broader import, the implicit theories framework - with its emphasis on growth, resilience, and flourishing - is consistent with recent calls for those who study "the good life" to more fully address the interplay among positive and negative attributes and experiences, including the process of growth following adversity (Wong, 2011), and with recent evidence that resilience, growth, and wellbeing are three of the most investigated concepts within the field of positive psychology (Donaldson, Dollwet, \& Rao, 2015). The implicit theories framework appears to warrant greater recognition regarding its relevance to the understanding of human flourishing by the science of wellbeing.

\section{Acknowledgments}

I thank Nancy Digdon, Russell Powell, Holli-Anne Passmore, and the anonymous reviewers for their comments on an earlier draft of this manuscript.

\section{Author}

Andrew J. Howell

MacEwan University

howella@macewan.ca

\section{Publishing Timeline}

Received 16 May 2016

Accepted 2 August 2016

Published 14 October 2016

\section{References}

Blackwell, L. S., Trzesniewski, K. H., \& Dweck, C. S. (2007). Implicit theories of intelligence predict achievement across an adolescent transition: A longitudinal study and an intervention. Child Development, 78(1), 246-263. http://dx.doi.org/10.1111/j.1467-8624.2007.00995.x

Burnette, J. L., O'Boyle, E. H., VanEpps, E. M., Pollack, J. M., \& Finkel, E. J. (2013). Mind-sets matter: A meta-analytic review of implicit theories and self-regulation. Psychological Bulletin, 139(3), 655-701. http://dx.doi.org/10.1037/a0029531

Burnette, J. L., Pollack, J. M., \& Hoyt, C. L. (2010). Individual differences in implicit theories of leadership ability and expectations: Predicting responses to stereotype threat. Journal of Leadership Studies, 3(4), 46-56. http://dx.doi.org/10.1002/jls.20138

Cameron, K. S., \& Spreitzer, G. M. (2012). Oxford handbook of positive organizational scholarship. New York, NY: Oxford University Press.

Chen, Z., DeWall, C. N., Poon, K.-T., \& Chen, E.-W. (2012). When destiny hurts: Implicit theories of relationships moderate aggressive responses to ostracism. Journal of Experimental Social Psychology, 48(5), 1029-1036. http://dx.doi.org/10.1016/j.jesp.2012.04.002

Cobb, R. A., DeWall, C. N., Lambert, N. M., \& Fincham, F. D. (2013). Implicit theories of relationships and close relationship violence: Does believing your relationship can grow relate to lower perpetration of violence? Personality and Social Psychology Bulletin, 39(3), 279-290. http://dx.doi.org/10.1177/0146167212473159

Coffey, J. K., Wray-Lake, L., Mashek, D., \& Branand, B. (2016). A multi-study examination of well-being theory in college and community samples. Journal of Happiness Studies, 17(1), 187-211.

http://dx.doi.org/10.1007/s10902-014-9590-8 
Cohen-Chen, S., Halperin, E., Crisp, R. J., \& Gross, J. J. (2014). Hope in the Middle East: Malleability beliefs, hope, and the willingness to compromise for peace. Social Psychological and Personality Science, 5(1), 67-75. http://dx.doi.org/10.1177/1948550613484499

Csikszentmihalyi, M. (1996). Finding flow: The psychology of engagement with everyday life. New York, NY: Basic Books.

Cury, F., Elliot, A. J., Da Foncesca, D., \& Moller, A. C. (2006). The social-cognitive model of achievement motivation and the $2 \times 2$ achievement goal framework. Journal of Personality and Social Psychology, 90(4), 666-679. http://dx.doi.org/10.1037/0022-3514.90.4.666

Dambrun, M., \& Ricard, M. (2011). Self-centeredness and selflessness: A theory of self-based psychological functioning and its consequences for happiness. Review of General Psychology, 15(2), 138-157. http://dx.doi.org/10.1037/a0023059

De Castella, K., Goldink, P., Jazaieri, H., Ziv, M., Dweck, C. S., \& Gross, J. J. (2013). Beliefs about emotion: Links to emotion regulation, well-being, and psychological distress. Basic and Applied Social Psychology, 35(6), 497-505. http://dx.doi.org/10.1080/01973533.2013.840632

Donaldson, S. I., Dollwet, M., \& Rao, M. A. (2015). Happiness, excellence, and optimal human functioning revisited: Examining the peer-reviewed literature linked to positive psychology. Journal of Positive Psychology, 10(3), 185-195. http://dx.doi.org/10.1080/17439760.2014.943801

Dweck, C. S. (1999). Self-theories: Their role in motivation, personality, and development. Philadelphia, PA: Psychology Press.

Dweck, C.S. (2007). Self-theories: The mindset of a champion. In T. Morris, P. Terry, \& S. Gordon (Eds.), Sport and exercise psychology: International perspectives. Morgantown, WV: Fitness Information Technology.

Dweck, C. S. (2012). Implicit theories. In P. Van Lange, A. Kruglanski, \& T. Higgins (Eds.), The handbook of theories of social psychology (Vol. 2) (pp. 43-61). Thousand Oaks, CA: Sage. http://dx.doi.org/10.4135/9781446249222.n28

Dweck, C. S., Chiu, C.-Y., \& Hong, Y.-Y. (1995). Implicit theories and their role in judgments and reactions: A world from two perspectives. Psychological Inquiry, 6(4), 267-285. http://dx.doi.org/10.1207/s15327965pli0604 1

Dweck, C. S., \& Leggett, E. L. (1988). A social-cognitive approach to motivation and personality. Psychological Review, 95(2), 256-273. http://dx.doi.org/10.1037/0033-295X.95.2.256

Franiuk, R., Cohen, C., \& Pomerantz, E. M. (2002). Implicit theories of relationships: Implications for relationship satisfaction and longevity. Personal Relationships, 9(4), 345-367. http://dx.doi.org/10.1111/1475-6811.09401

Fredrickson, B. L. (2001). The role of positive emotions in positive psychology: The broaden-and-build theory of positive emotions. American Psychologist, 56(3), 218-226. http://dx.doi.org/10.1037/0003$\underline{\text { 066X.56.3.218 }}$

Grant, A. M., Curtayne, L., \& Burton, G. (2009). Executive coaching enhances goal attainment, resilience, and workplace well-being: A randomised controlled study. Journal of Positive Psychology, 4(5), 396407. http://dx.doi.org/10.1080/17439760902992456

Heslin, P. A., Vandewalle, D., \& Latham, G. P. (2008). Keen to help? Managers' implicit person theories and their subsequent employee coaching. Personnel Psychology, 59(4), 871-902. http://dx.doi.org/10.1111/j.1744-6570.2006.00057.x

Howell, A. J., Passmore, H.-A., \& Holder, M. R. (2015). Implicit theories of well-being predict well-being and the endorsement of therapeutic lifestyle changes. Journal of Happiness Studies. 1-17. http://dx.doi.org/10.1007/s10902-015-9697-6

Huta, V. (2016). An overview of hedonic and eudaimonic well-being concepts. In L. Reinecke \& M. B. Oliver (Eds.), Handbook of media use and well-being: International perspectives on theory and research on positive media effects (pp. 14-33). New York, NY: Routledge.

Jayawickreme, E., Forgeard, M. J. C., \& Seligman, M. E. P. (2012). The engine of well-being. Review of General Psychology, 16(4), 327-342. http://dx.doi.org/10.1037/a0027990 
Job, V., Dweck, C. S., \& Walton, G. M. (2010). Ego depletion - Is it all in your head? Implicit theories about willpower affect self-regulation. Psychological Science, 21(11), 1686-1693. http://dx.doi.org/10.1177/0956797610384745

Kappes, A., \& Schikowski, A. (2013). Implicit theories of emotion shape regulation of negative affect. Cognition and Emotion, 27(5), 952-960. http://dx.doi.org/10.1080/02699931.2012.753415

Karafantis, D. M., \& Levy, S. R. (2004). The role of children's lay theories about the malleability of human attributes in beliefs about and volunteering for disadvantaged groups. Child Development, 75(1), 236250. http://dx.doi.org/10.1111/j.1467-8624.2004.00666.x

Kern, M. L., Waters, L. E., Adler, A., \& White, M. A. (2015). A multidimensional approach to measuring well-being in students: Application of the PERMA framework. Journal of Positive Psychology, 10(3), 262-271. http://dx.doi.org/10.1080/17439760.2014.936962

Keyes, C. L. M. (2005). Mental illness and/or mental health? Investigating axioms of the complete state model of health. Journal of Consulting and Clinical Psychology, 73(3), 539-548. http://dx.doi.org/10.1037/0022-006X.73.3.539

King, L. A. (2001). The health benefits of writing about life goals. Personality and Social Psychology Bulletin, 27(7), 798-807. http://dx.doi.org/10.1177/0146167201277003

Knee, C. R. (1998). Implicit theories of relationships: Assessment and prediction of romantic relationship initiation, coping, and longevity. Journal of Personality and Social Psychology, 74(2), 360-370. http://dx.doi.org/10.1037/0022-3514.74.2.360

Knee, C. R., Patrick, H., \& Lonsbary, C. (2003). Implicit theories of relationships: Orientations toward evaluation and cultivation. Personality and Social Psychology Review, 7(1), 41-55. http://dx.doi.org/10.1207/S15327957PSPR0701 3

Knee, C. R., Patrick, H., Vietor, N. A., \& Neighbors, C. (2004). Implicit theories of relationships: Moderators of the link between conflict and commitment. Personality and Social Psychology Bulletin, 30(5), 617-628. http://dx.doi.org/10.1177/0146167203262853

Knee, C. R., \& Petty, K. N. (2013). Implicit theories of relationships: Destiny and growth beliefs. In J. A. Simpson \& L. Campbell (Eds.), The Oxford handbook of close relationships (pp. 183-198). New York, NY: Oxford.

Kneeland, E. T., Nolen-Hoeksema, S., Dovidio, J. F., \& Gruber, J. (2016). Emotion malleability beliefs influence the spontaneous regulation of social anxiety. Cognitive Therapy and Research, 40(4), 496-509. http://dx.doi.org/10.1007/s10608-016-9765-1

Lambert D'raven, L., \& Pasha-Zaidi, N. (2016). Using the PERMA model in the United Arab Emirates. Social Indicators Research, 125(3), 905-933. http://dx.doi.org/10.1007/s11205-015-0866-0

Lilgendahl, J. P., McLean, K. C., \& Mansfield, C. D. (2013). When is meaning making unhealthy for the self? The roles of neuroticism, implicit theories, and memory telling in trauma and transgression memories. Memory, 21(1), 79-96. http://dx.doi.org/10.1080/09658211.2012.706615

Louis, M. C. (2011). Strengths interventions in higher education: The effect of identification versus development approaches on implicit self-theory. Journal of Positive Psychology, 6(3), 204-215. http://dx.doi.org/10.1080/17439760.2011.570366

Lyubomirsky, S., \& Layous, K. (2013). How do simple positive activities increase well-being? Current Directions in Psychological Science, 22(1), 57-62. http://dx.doi.org/10.1177/0963721412469809

Lyubomirsky, S., Sheldon, K. M., \& Schkade, D. (2005). Pursuing happiness: The architecture of sustainable change. Review of General Psychology, 9(2), 111-131. http://dx.doi.org/10.1037/10892680.9.2.111

Mauss, I. B., Savino, N. S., Anderson, C. L., Weisbuch, M., Tamir, M., \& Laudenslager, M. L. (2012). The pursuit of happiness can be lonely. Emotion, 12(5), 908-912. http://dx.doi.org/10.1037/a0025299

Mauss, I. B., Tamir, M., Anderson, C. L., \& Savino, N. S. (2011). Can seeking happiness make people unhappy? Paradoxical effects of valuing happiness. Emotion, 11(4), 807-815.

http://dx.doi.org/10.1037/a0022010 
McNulty, J. K., \& Fincham, F. D. (2012). Beyond positive psychology? Toward a contextual view of psychological processes and well-being. American Psychologist, 67(2), 101-110. http://dx.doi.org/10.1037/a0024572

Molden, D. C., \& Dweck, C. S. (2000). Meaning and motivation. In C. Sansone \& J. M. Harackiewicz (Eds.), Intrinsic and extrinsic motivation: The search for optimal motivation and performance (pp. 131-159). San Diego, CA: Academic Press. http://dx.doi.org/10.1016/B978-012619070-0/50028-3

Molden, D. C., \& Dweck, C. S. (2006). Finding "meaning" in psychology: A lay theories approach to selfregulation, social perception, and social development. American Psychologist, 61(3), 192-203. http://dx.doi.org/10.1037/0003-066X.61.3.192

Mueller, C. M., \& Dweck, C. S. (1998). Praise for intelligence can undermine children's motivation and performance. Journal of Personality and Social Psychology, 75(1), 33-52. http://dx.doi.org/10.1037/0022$\underline{3514.75 .1 .33}$

Nussbaum, A. D., \& Dweck, C. S. (2008). Defensiveness vs. remediation: Self-theories and modes of selfesteem maintenance. Personality and Social Psychology Bulletin, 34(5), 599-612. http://dx.doi.org/10.1177/0146167207312960

Plaks, J. E., Grant, H., \& Dweck, C. S. (2005). Violations of implicit theories and the sense of prediction and control: Implications for motivated person perception. Journal of Personality and Social Psychology, 88(2), 245-262. http://dx.doi.org/10.1037/0022-3514.88.2.245

Plaks, J. E., Levy, S. R., \& Dweck, C. S. (2009). Lay theories of personality: Cornerstones of meaning in social cognition. Social and Personality Psychology Compass, 3(6), 1069-1081. http://dx.doi.org/10.1111/j.1751-9004.2009.00222.x

Proulx, T., \& Inzlicht, M. (2012). The five "A"s of meaning maintenance: Finding meaning in the theories of sense-making. Psychological Inquiry, 23(4), 317-335. http://dx.doi.org/10.1080/1047840X.2012.702372

Ramos, S. J., \& Puccio, G. J. (2014). Cross-cultural studies of implicit theories of creativity: A comparative analysis between the United States and the main ethnic groups in Singapore. Creativity Research Journal, 26(2), 223-228. http://dx.doi.org/10.1080/10400419.2014.901094

Rattan, A., Good, C., \& Dweck, C. S. (2012). "It's ok - not everyone can be good at math": Instructors with an entity theory comfort (and demotivate) students. Journal of Experimental Social Psychology, 48(3), 731-737. http://dx.doi.org/10.1016/j.jesp.2011.12.012

Rusk, R. D., \& Waters, L. E. (2013). Tracing size, reach, impact, and breadth of positive psychology. Journal of Positive Psychology, 8(3), 207-221. http://dx.doi.org/10.1080/17439760.2013.777766

Ryff, C. D. (1989). Happiness is everything, or is it? Explorations on the meaning of psychological wellbeing. Journal of Personality and Social Psychology, 57(6), 1069-1081. http://dx.doi.org/10.1037/0022$\underline{3514.57 .6 .1069}$

Sallquist, J., Eisenberg, N., Spinrad, T. L., Eggum, N. D., \& Gaertner, B. M. (2009). Assessment of preschoolers' positive empathy: Concurrent and longitudinal relations with positive emotion, social competence, and sympathy. Journal of Positive Psychology, 4(3), 223-233. http://dx.doi.org/10.1080/17439760902819444

Schleider, J. L., Abel, M. R., \& Weisz, J. R. (2015). Implicit theories and youth mental health problems: A random-effects meta-analysis. Clinical Psychology Review, 35, 1-9. http://dx.doi.org/10.1016/j.cpr.2014.11.001

Schneider, S. L. (2001). In search of realistic optimism: Meaning, knowledge, and warm fuzziness. American Psychologist, 56(3), 250-263. http://dx.doi.org/10.1037/0003-066X.56.3.250

Schumann, K., Zaki, J., \& Dweck, C. S. (2014). Addressing the empathy deficit: Beliefs about the malleability of empathy predict effortful responses when empathy is challenging. Journal of Personality and Social Psychology, 107(3), 475-493. http://dx.doi.org/10.1037/a0036738

Seligman, M. E. P. (2011). Flourish: A visionary new understanding of happiness and well-being. New York, NY: Free Press.

Tamir, M., John, O. P., Srivastava, S., \& Gross, J. J. (2007). Implicit theories of emotion: Affective and social outcomes across major life transitions. Journal of Personality and Social Psychology, 92(4), 731-744. http://dx.doi.org/10.1037/0022-3514.92.4.731 
Vella, S., \& Gilbert, W. (2014). Coaching young athletes to positive development: Implications for coach training. In A. R. Gomes (Ed.), Positive human functioning from a multidimensional perspective, Vol. 3: Promoting high performance (pp. 83-105). Happauge, NY: Nova Science.

Walton, G. M. (2014). The new science of wise psychological interventions. Current Directions in Psychological Science, 23(1), 73-82. http://dx.doi.org/10.1177/0963721413512856

Wong, P. T. P. (2010). Meaning therapy: An integrative and positive existential psychotherapy. Journal of Contemporary Psychotherapy, 40(2), 85-93. http://dx.doi.org/10.1007/s10879-009-9132-6

Wong, P. T. P. (2011). Positive psychology 2.0: Towards a balanced interactive model of the good life. Canadian Psychology, 52(2), 69-81. http://dx.doi.org/10.1037/a0022511

Yeager, D. S., \& Dweck, C. S. (2012). Mindsets that promote resilience: When students believe that personal characteristics can be developed. Educational Psychologist, 47(4), 302-314. http://dx.doi.org/10.1080/00461520.2012.722805

Yeager, D. S., Johnson, R., Spitzer, B. J., Trzesnieski, K. H., Powers, J., \& Dweck, C. S. (2014). The farreaching effects of believing that people can change: Implicit theories of personality shape stress, health, and achievement during adolescence. Journal of Personality and Social Psychology, 106(6), 867884. http://dx.doi.org/10.1037/a0036335

Yeager, D. S., Miu, A. S., Powers, J., \& Dweck, C. S. (2013). Implicit theories of personality and attributions of hostile intent: A meta-analysis, an experiment, and a longitudinal intervention. Child Development, 84(5), 1651-1667. http://dx.doi.org/10.1111/cdev.12062

Yeager, D. S., Trzesniewski, K. H., Tirri, K., Mokelainen, P., \& Dweck, C. S. (2011). Adolescents' implicit theories predict desire for vengeance after peer conflicts: Correlational and experimental evidence. Developmental Psychology, 47(4), 1090-1107. http://dx.doi.org/10.1037/a0023769 